\title{
Design and Implementation of a Pivotal Unit in a Games Technology Degree
}

\author{
Shri Rai*, Chun Che Fung** and Arnold Depickere*** \\ *School of Information Technology, \\ **Centre for Enterprise Collaboration in Innovative Systems, \\ ***Division of Arts \\ Murdoch University, Murdoch, Western Australia, 6150, Australia \\ \{s.rai | l.fung | a.depickere\}@murdoch.edu.au
}

\begin{abstract}
This paper reports the development and running of the first Games Development and Programming unit at Murdoch University, Western Australia. Unlike other Games courses which have been repackaged or re-modeled from existing multimedia courses, the proposed course and units are focused on meeting the needs of the industry and high level of academic standard. As such, great demands have been placed on the students. The unit objectives, structure and examples of assignments from the first batch of students are described in this paper. Experience has shown that the students were able to perform well with positive encouragement. Ability to work in a team also proved to be an important factor. This has shown to be related to the standard of the students' work and it is also an essential attribute expected by the industry.
\end{abstract}

\section{Introduction}

It has been recognized that digital and computer games is the fastest growing industry in Information Technology. According to the Game Developers Association of Australia (GDAA), an estimated amount of \$A40.9 billion dollars of interactive video games were sold in 2002 [1]. Globally, the current figure is expected to exceed $\$ 50$ billion. According to the same source, in 2002, Australians have spent \$825 million on games hardware, software and the figures are increasing quickly every year since then.

Apart from the gowing markets, computer games are also evolving and advancing rapidly in terms of complexity, realism and the overall design. Hence, there is a need for a new generation of professionals in the industry. The games industry requires not only computer programmers but also people skilled in other areas. The Australian Government's Culture and Recreation Portal [1] indicates that the games industry has a need for specialists in various areas which includes: animation skills; technical design; script or play writers; 3D graphics; game project management; film making and character design. Although not mentioned at the portal, artists are also needed along with people skilled in mathematics and physics. The government portal also indicates that just like any other industry, basic or generic skills required are: 
teamwork; communication skills; problem solving; adaptivity and creative thinking. In order to survive in the games industry, people working in this industry have to be prepared to face relentless challenges to their creativity and their technical skills. This sets the games industry apart from the rest of the Information and Communication Technology industry.

In Western Australia (WA), market surveys had showed that there was a demand for a degree program in the development of computer games. However, it was discovered that there were no tertiary institutions at that time offering such a program. Since there are a number of software companies producing games in WA, it had become apparent that a gap existed between the demand of the industry and supply from the tertiary institutions.

Through extensive consultation with industry and background research it was acknowledged that a games technology degree cannot be offered as a re-packaged version of our existing Multimedia Degree although such an approach was appealing from the point of view of the costs involved. The idea of modifying several aspects of the multimedia degree to fit into a games technology degree was also rejected even though it was understood that a number of other institutions had adopted such an approach. It was decided that these two approaches would not do justice to the games technology degree we wanted to offer.

Design of the Games Technology Program has been based on the guiding document by the International Game Developers Association's IGDA Curriculum Framework [2]. Both the Games Technology degree program and the new units in the degree went through a number of formal academic planning processes required by the university and the university's academic council. Within the university, the planning processes usually happen at least one year in advance of the degree and units being offered. This gives sufficient time for the consultation and planning of the new programs and units.

After extensive consultation within the university and with the industry advisory committee, it was decided that the new degree program will have a common first year structure keeping it in line with the other current degree programs. Under such a structure, the students are prepared with common or foundation units and then they pursue specific majors or minors in the second part of the program (course). The first year included a number of introductory units such as Fundamentals of Computer Systems and Java Programming, and a Computational Mathematics (also known as Discreet Mathematics or digital Mathematics) unit. In this mathematics unit, students learn the basics of linear algebra. Due to nature of the programs, not all students will be enrolled in all the programming or the mathematics units. The units the students enrol in is largely determined by the specialisation they wish to pursue when they enter the second year of their degree program/major.

Students who wanted to specialise in games technology would need to complete a first semester, second year unit called Games Design and Programming (GDP). Failure in this unit means that students could not continue with the games technology specialisation. Students enrolling in GDP would have done at least two units with computer programming content. GDP also requires knowledge of Computer Graphics and Computational Mathematics. Hence, GDP is the pivotal unit within the Games degree course. 
This paper aims to report on the detailed objectives, organisation and works submitted by the students after one year of running GDP. It is expected that through sharing of the experience and feedbacks on the program will enable further improvement of the unit and the program.

\section{Games Design and Programming}

As pointed out in the previous section, the Games Design and Programming unit is a pivotal unit in the Games Technology course. Subsequent core units in the games technology program/major are based on the GDP unit as a pre-requisite. Also, in order to provide flexibility and wider choices to the students, those who would like to study GDP would need to cover the elements of computer graphics and mathematics. GDP would also need to cover basic Newtonian physics, Artificial Intelligence and elements of Media Studies. All these are indicated in the IGDA's Curriculum Framework. Along with GDP, students also need separate units called Intelligent Systems and Computer Graphics Principles and Programming for the subsequent advanced units in the Games Technology degree program. It was felt that from the very first games related unit in the degree program, students would have to develop games as part of their final project. This requirement determined the content of the Games Design and Programming unit. The final description of the unit in the handbook is stated below:

"This unit covers introduction to games design and programming from a theoretical and practical points of view. The unit includes game theory, data structures, and play-testing, as well as the physics of games programming. Further work covers non-linearity, level-design and intelligent agents. Practical rules for writing games programs are developed and applied."

The declared aims of GDP are:

1. to introduce students to the field of Games Design and Programming and to appreciate the multidisciplinary nature of this field.

2. to introduce students to the essential concepts and techniques through practice work based on developing programs that create interactive visual imagery.

3. to get students to acquire independent self-learning skills.

The listed learning objectives of the unit are:

1. to find out about current applications of computer graphics in games;

2. to learn about the techniques and algorithms used for developing games applications involving both 2D and 3D objects;

3. to learn the essential theory behind games design;

4. to be able to design and implement simple computer games in $\mathrm{C} / \mathrm{C}++$ including the use of library functions from various APIs (Application Programmer's Interface). 
5. to acquire some ability to extend current skills unaided.

It was felt that students had been exposed to Java but not to $\mathrm{C} / \mathrm{C}++$. It was decided that the computer graphics unit would use $\mathrm{C}$ as the implementation language whereas, GDP would use $\mathrm{C}++$. This was to give students exposure to these languages as well as to improve their programming skills using a variety of programming languages. Both of these units contain a heavy programming content.

As the computer graphics unit was not a pre-requisite to GDP, selected sections of the graphics unit was taught in an intensive approach in GDP. The only language used in GDP was C++. In addition, in line with other units being taught in the university, GDP was taught in a thirteen week semester. The following table lists the topics covered and their duration in weeks.

Table 1: Course structure and topics taught in GDP unit

\begin{tabular}{|l|c|c|l|}
\hline $\begin{array}{l}\text { Starting } \\
\text { Week }\end{array}$ & $\begin{array}{c}\text { No. of } \\
\text { Weeks }\end{array}$ & $\begin{array}{c}\text { Topic } \\
\text { No. }\end{array}$ & Topic Title \\
\hline 1 & 1 & 1 & Games in Context \\
\hline 2 & 1 & 2 & History of Games \\
\hline 3,4 & 2 & 3 & Game Graphics \\
\hline $5,6,7$ & 3 & 4 & Game Design \\
\hline 8 & 1 & 5 & Virtual Worlds \\
\hline 9 & 1 & 6 & Game Physics/Mathematics \\
\hline 10,11 & 2 & 7 & Game AI \\
\hline 12 & 1 & 8 & Game Engines \\
\hline 13 & 1 & 9 & Network Games \\
\hline
\end{tabular}

Staff with various backgrounds was called on to teach the unit. Staff specialising in literary and media art forms taught "Games in Context", "History of Games" and part of Game Design where narrative and narrative structures are examined. A person from the games industry (game developer) was employed to teach the rest of "Games Design" as well as "Virtual Worlds, "Game Engines” and "Network Games". Staff with a Computer Science background taught "Game Graphics”, "Game AI”, "Game Physics/Mathematics”. The finer points of object orientation using C++ were covered on demand - when students needed to know so that they could do the implementation. We would like to note that our experience in teaching Computer Science indicated that teaching object orientation in a formal and structured fashion (as taught in traditional Computer Science schools) is not as effective as teaching “on demand”. As it can be seen, the topics are interdisciplinary and therefore the staff teaching the unit came from different disciplines.

The practical work that student did was a mix of individual work as well as group work. The individual assessments were needed to ensure that each student would have the necessary skills. Group work was encouraged as students needed to learn how to work co-operatively and therefore acquire group-work skills. This group-work was needed because games are not designed and built by individuals but teams of 
people. Although group-work was strongly encouraged when students were working on the projects and assignment, group-work was not made mandatory.

During the semester, staff handling the practical aspects of the unit kept praising the students' ability to understand the more difficult aspects of the unit. This was done to encourage them not to give up. There were some topics which some students found too difficult to follow. The first assignment was the construction of a virtual tour of part of the university's campus. This was due half way into the semester. There was approximately 50-50 split in the assignment quality. Students had to demonstrate the tour in class. To encourage the less able students, staff did not criticise the assignments. It was felt that there was no need to criticise as it was patently obvious to everyone - including the students concerned - that the work was no good when viewed alongside the better assignments. Instead staff chose to highlight something (in the poorer as well as the better assignments) that the students had spent some time on and commenting on how well that was done. The real motive for all this was that the drop out rate would not be high in the unit.

Assessment in the unit was such that to pass the unit, students needed to have an understanding of what was taught in the unit. However, to get distinction grades, students needed to go beyond what was covered in the unit. They had to find out additional tools and techniques to use to build their games. The students were also told from the very beginning that their work would be exhibited publicly and their names would be associated with the work they produced.

\section{Results from the first class of students}

All students who attempted GDP and sat the exam passed the unit. There was an unusually high number of distinction or higher grades awarded in the unit. The following are the descriptions and screenshots of some assignments produced by the students.

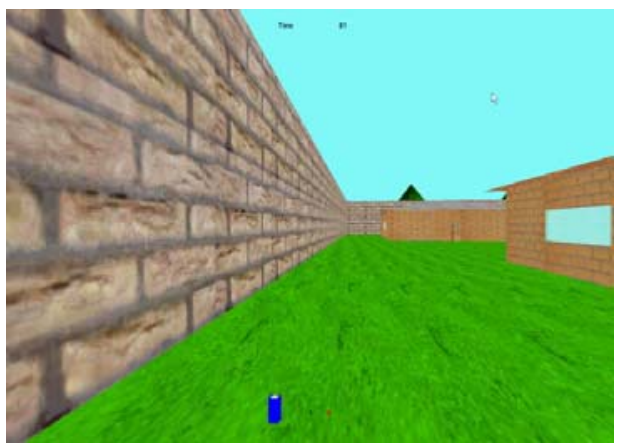

The object of this game is to find a number of lost books. There is only a limited amount of time to get the books. Carrying the books too long would tire the player out and the player would have to drop some books to continue. The game has a 3D environment and use of graphics to illustrate a virtual world. The player has to strike a balance between time and resources.

Fig. 1: Screen shot of "The Books are Missing” 


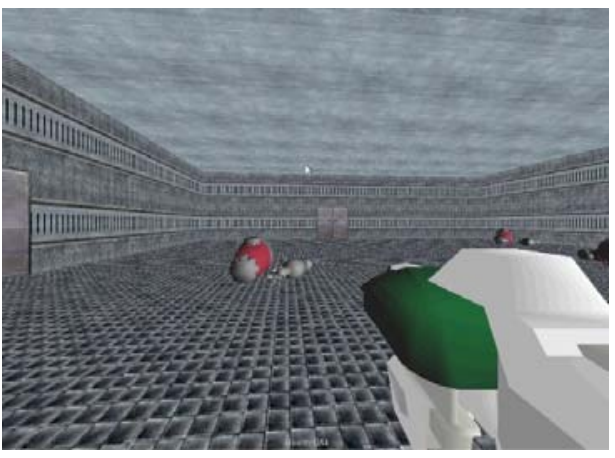

Fig. 2: Screen shot of the "Grunge"

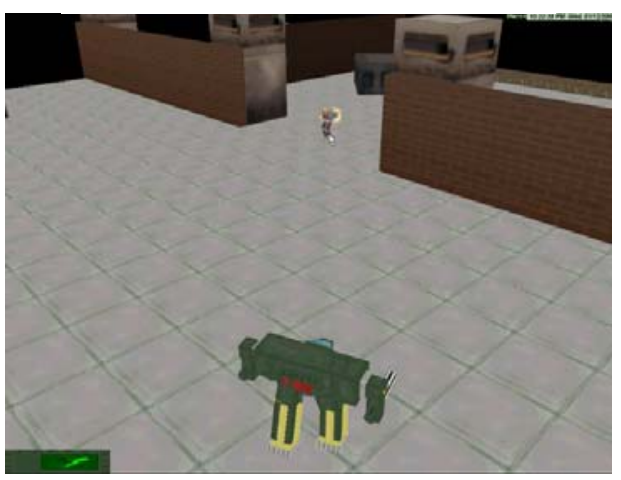

Fig. 3: Screen shot of "Robowar"

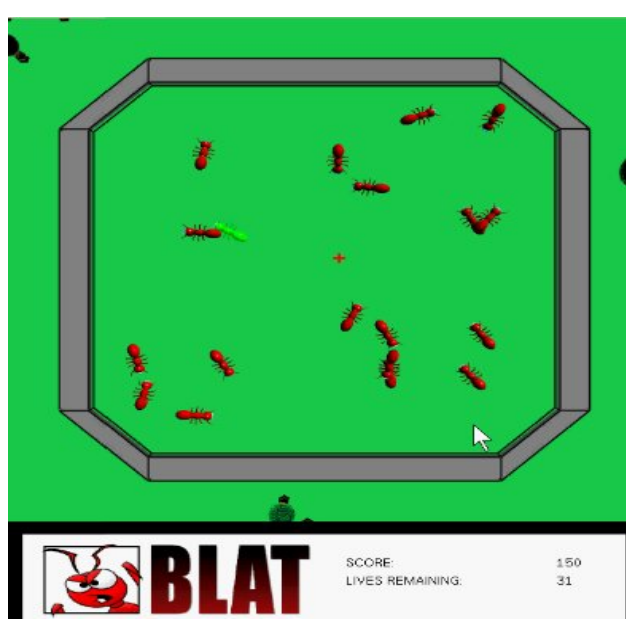

Fig. 4: Screen shot of "BLAT"
The object of the game in Figure 2 is to capture the "nerve centre" guarded by robots. Similar to "Lost Books" this game utilised 3D graphics to create a virtual environment where the robots roam and destroy the enemies. There is a fair amount of point and shoot actions with sound. The program demands fast reaction and regeneration of the graphics.

The object of the game in Figure 3 is to destroy the robots guarding a city and capture the city. The AI in the robot guards enables the robots to chase the player if the player comes too close. In addition to the $3 \mathrm{D}$ environment and graphics, the students have put in a fair amount of effort in designing the robots. They even included an "Evolution" of the robots which illustrated the development of the game concept.

The objective of the game in Figure 4 is to kill the red fire ants and move on to the next level of the game. This project won the industry prize. If a wrong ant is killed, the red ant will multiply. The twist to the game is that the movement of the cursor is purposely designed to be sluggish and the player cannot just chase the ants. Strategic placement is needed. This creates a high level of addictiveness and challenge. It is the most complete game as compared to the rest. Although the graphics are not as sophisticate as the others, the students have demonstrated high level of professionalism in the organisation and concept for the games. The documentation also included marketing materials with sense of humour and fun. This captured the main objective of the game development unit. 


\section{Discussion}

Feedbacks and surveys from running of the unit for the first time have provided many lessons to be learnt - for both the students and staff. It appears that there was high level of competition amongst the various teams. It also emerged that not everyone would like to work in groups. A few students were not invited to join groups because they were known by the other students as not being capable (not technically inclined). A smaller number of students chose to work on their own because they felt that the others were not as good as they were and would therefore contributed negatively towards the quality of the project. This is a significant phenomenon as the students are unlikely to work on their own in times to come. It proved to be a challenge to encourage the students to overcome the differences and in managing the group dynamics. This inequity in group formation needs to be resolved by formal intervention. Formal intervention, however, was not used as it was felt that students would naturally form groups to reduce the workload as the both the assignment and project in the unit were made substantial to "encourage" students to work on these tasks in groups. Those students who deliberately chose to work on their own managed a credit or better. Those students who were not invited to join groups did marginally with a couple of them failing the project. Those who worked in groups usually got a distinction or a high distinction.

It was also noted that projects which had good graphics had a less sophisticated gameplay compared to those projects which had simpler graphics. This was a time problem as there was only a limited amount of time available to complete the project. Some students chose to spend more time on graphics at the expense of game play and vice versa.

A number of the better projects were short listed for an industry selected award. Eventually, a team based project won. The following is from an industry reviewer concerning this project:

"It had a distinctive logo, reasonably good graphics; multiple levels of increasing difficulty, randomisation and it could turn out to be quite addictive. As well it had a "designed" instruction manual which also reflects a sense of humour. The accompanying documentation seemed like the authors actually still enjoy it, even after all their hard work to create it."

The only one-person project short listed had an honourable mention but industry criticised the fact that the student did not want to work in a team. In the words of an industry reviewer:

"This is an excellent attempt by a one-person team. The design process has been thought through and there has been a genuine attempt to aim the game at a particular segment of the market. The collision detection actually works, the response rate to the controls is good and you can actually go inside the buildings - it's a pity that there is not very much in there to explore and do."

and also, 
"I would suggest that the creator learns to work in a team as future employers may see him as a potential management problem."

Obviously, working alone, the student could not put in the details inside his buildings. It appears that there were two very important motivation factors behind the students' performance. One was the knowledge that their work would be exhibited publicly and that their names would also be associated with the work they did. It is possible that Maslow's [3] "Esteem needs" may be at work here. It was obvious that for a number of students, the need to stand out was important.

The second factor appears to be the encouragement they obtained. The original intention of this encouragement was to reduce student drop-outs. This encouragement had an unforseen side-effect. It turns out that students' motivation to produce good work increased. It is possible that Attribution theory [4-6] may explain this. Students were being constantly told that there were good at the work they were doing. Staff were inadvertently encouraging students' belief that they were "actually" capable. This was not an issue with students who were actually capable but it became critical with students whose initial work was not very good. These students decided to apply themselves to show that they were good. Unfortunately, this did not work with all students as some students received a negative message from their peers who would not let weaker students join their teams.

There are some lessons to be learnt. Team building requires further attention. This is crucial as the industry representative's comments indicate. It was realised that there is a need to fine tune the way the students were treated and encouraged. The work and standard expected from the students have been very demanding and will continue to be so. A number of students whom appeared to be not able to cope have proved to be able to complete the tasks and even did well. They did this through sheer hard work at the expanse of their performance in other units. We belief that these students sacrificed their performance in their other units because they felt that they were good in GDP and were determined to prove it.

\section{Conclusion}

The Games Technology course is the first of its kind on offer by tertiary institutions in Western Australia. The course generated high level of interests and the number of initial applications has proved the course to be a very popular choice. The development and running of the pivotal Games Development and Programming unit have been a rewarding experience for both students and staff. While the course was initially designed to meet the needs of the industry, the concept and content of the unit have fulfilled and far exceeded the expectations from the technical, academic, education and training viewpoints. Students from the pilot second year unit have demonstrated high levels of professionalism in their ability for game development. The ability of the students was also demonstrated when one of the project submissions was awarded a prize in an industry competition. We can also report that the Games Technology students now command respect amongst their peers in other ICT majors. As one Computer Science major remarked during a staff and student discussion: "We 
are no match for them [Game Technology students]... they are like gods among men". One of the reasons for the success can be attributed to the positive encouragement and support given to the students. It also became clear that there were attitude and management issues which the students and staff have to deal with. In particular, the need for the students to be able to work in a team has shown to correlate with the quality and level of the work being produced. Also, the students' perceptions of their own ability determine how much work they will put in to achieve some objective even if this means sacrificing other goals. There is, unfortunately, a serious issue which is highlighted by the Computer Science major's remark: there are no female students who have survived the demands of the pivotal unit even though a number of female students were enrolled at the beginning. This is a very difficult and vexing problem that we are now grappling with. Obviously, all these issues will have important lessons for the students as well as staff and attention will be paid to subsequent offerings of the unit.

\section{References}

1. Australian Government Cultural and Recreation Portal, "Digital games industry in Australia”, URL: http://www.cultureandrecreation.gov.au/articles/digitalgames/, Accessed: $25^{\text {th }}$ March, 2005

2. IGDA (2003). IGDA Curriculum Framework: The Study of Games and Game Development. San Francisco, International Game Developers Association.

3. Maslow, A. H. (1971). "The farther reaches of human nature." New York, Viking Press.

4. Bem, D. (1972). "Self-perception theory." Advances in experimental social psychology,. L. Berkowitz. New York, Academic Press. 6

5. Miller, R., Brickman, P., Bolen, D. (1975). "Attribution versus persuasion as a means of modifying behavior." In Journal of Personality and Social Psychology 31: 430-441.

6. Heider, F. (1958). The psychology of interpersonal relations. New York, Wiley. 